\title{
Distribuição Espacial de Depósitos Irregulares de Lixo em Belém: estudo de alguns trechos das margens de bacias urbanas
}

\author{
Spatial Distribution of Deposits Unauthorized Garbage in Belém: study of some parts \\ of margins drainages urban
}

\begin{abstract}
Distribución Espacial de Depósitos Irregulares de Basura em Belém: estúdio de algunos trechos de las margenes de bacias urbanas
\end{abstract}

Diego Andrews Hayden ${ }^{1}$

\begin{abstract}
RESUMO: A gestão de resíduos é um tema global de grande relevância na atualidade devido a vários fatores. No Brasil, a questão da disposição do lixo e tratamento de resíduos sólidos ainda está pouco amadurecida e não se encontra equacionada à outras atividades do Estado. $\mathrm{O}$ crescimento exponencial da distribuição espacial dos lixões tem como palco privilegiado as metrópoles. Em Belém, a espacialidade dos lixões é diversa e encontram-se por todo o município em terrenos baldios, cantos de ruas e beira de canais. Tal fato é recorrente há anos tornando-se um grande desafio que só poderá ser resoluto através de um amplo rol de cooperação entre o poder público e a sociedade civil com base em políticas públicas e educação ambiental, entre outros. Assim, este trabalho objetiva fomentar o debate sobre a responsabilidade do Estado no que diz respeito à existência e espacialização de depósitos irregulares de lixo urbanos nas margens de canais, situados em zona periférica do município de Belém. Os procedimentos ajudaram a constatar que os depósitos irregulares de lixo se espalham homogeneamente por todos os lados em quantidades diferenciadas, sobretudo de entulho, madeira/podas de árvores e lixo doméstico.
\end{abstract}

PALAVRAS-CHAVE: Depósitos irregulares de lixo. Canais de drenagem. Resíduos sólidos. Responsabilidade do Estado.

ABSTRACT: Waste management is a global issue of great relevance today due to several factors. In Brazil, the issue of garbage disposal and solid waste treatment is not yet mature and is not equated with other State activities. The exponential growth of the spatial distribution of dumps has as its privileged stage the metropolises. In Belém, the spatiality of the garbage dumps is diverse and found throughout the municipality on vacant lots, street corners, and canalside. This fact has been recurring for years and has become a major challenge that can only be resolved through a wide range of cooperation between public power and civil society based on public policies, environmental education, among others. Thus, this paper aims to foster the debate on State Responsibility regarding the existence and spatialization of irregular urban garbage dumps on the edge of canals located in the peripheral zone of the municipality of Belém. The procedures helped to find that irregular deposits of garbage is spread homogeneously on all sides in different amounts, especially debris, wood / tree pruning and household waste.

KEYWORDS: Irregular garbage dumps. Watercourse. Solid waste. Responsibility of the State.

\footnotetext{
1 Universidade Federal do Pará. R. Augusto Corrêa, 01 - Guamá, Belém - PA, 66075-110. andrews.2087@hotmail.com.
} 
RESUMEN: La gestión de residuos es un tema global de gran relevancia hoy en día debido a varios factores. En Brasil, el tema de la eliminación de basura y el tratamiento de residuos sólidos aún no está maduro y no se equipara con otras actividades del Estado. El crecimiento exponencial de la distribución espacial de los vertederos tiene como escenario privilegiado las metrópolis. En Belém, la espacialidad de los vertederos de basura es diversa y se encuentra en todo el municipio en terrenos baldíos, esquinas y canales. Este hecho ha sido recurrente durante años y se ha convertido en un desafío importante que solo puede resolverse mediante una amplia gama de cooperación entre el poder público y la sociedad civil basada en políticas públicas, educación ambiental, entre otros. Por lo tanto, este documento tiene como objetivo fomentar el debate sobre la responsabilidad del Estado con respecto a la existencia y la espacialización de los vertederos urbanos irregulares en el borde de los canales ubicados en la zona periférica del municipio de Belém. la basura se esparce homogéneamente por todos lados en diferentes cantidades, especialmente escombros, poda de madera / árboles y desechos domésticos.

PALABRAS-CLAVE: Depósitos irregulares de basura. Canales de drenaje. Residuos sólidos. Responsabilidad del Estado.

\section{INTRODUÇÃO}

A cidade de Belém, no estado do Pará, está localizada em uma península cercada ao sul pelo rio Guamá, a oeste pela baía do Guajará, ao norte pelo furo do Maguari e a leste se limitando com o município de Ananindeua, ou seja, esta é uma cidade banhada por rios e inúmeros afluentes, conhecidos popularmente como igarapés que são, em grande parte, historicamente, aterrados e retificados, em decorrência de processos de ocupação urbana, perdendo, assim, sua importância sociocultural anterior (lazer, subsistência e mobilidade, entre outros).

De forma geral, essas áreas são povoadas por migrantes do interior do estado do Pará e/ou estados vizinhos, que enfrentam os mais sérios problemas socioambientais (poluição, criminalidade, pobreza e exclusão social, entre outros) (SANTOS, V., 2012), atrelados a sucessivos processos contraditórios de concentração de renda e de terra e pela ocupação desordenada do espaço urbano, nesse caso em Belém.

A cidade de Belém passou por vários processos de transformação de sua paisagem durante a segunda metade do século XX, sobretudo em áreas de baixadas, frutos de pressão popular e de mediação de políticas públicas de urbanização e saneamento, que visam ou visaram a resolução de problemas habitacionais e a incorporação dos igarapés e rios à paisagem urbana em um discurso de modernidade que visava o "oferecimento" de novos serviços e a melhoria da qualidade de vida para a população.

A área de estudo compreende um espaço de aproximadamente 12 quilômetros de extensão na Bacia Hidrográfica do Una, cidade de Belém, e os canais São Joaquim e o canal Água Cristal, localizada na confluência de seis bairros de Belém: Marambaia, Val-de-Cans, 
Sacramenta, Maracangalha, Barreiro e Telégrafo (conforme a Figura 1). Essa área está inserida em um amplo espaço que sofreu intervenção estatal no último quarto do século $X X$, devido ao projeto de macrodrenagem da Bacia do Una por intermédio do programa de "Recuperação da Baixadas de Belém”, implementado entre 1993 e 2004 (SANTOS, V., 2012), que objetivava o aterramento de áreas alagadas, a abertura de vias de mobilidade e a criação de um amplo sistema de drenagem para acúmulo e escoamento das águas das chuvas com fins de evitar as inundações.

Figura 1 - Localização da área de estudo

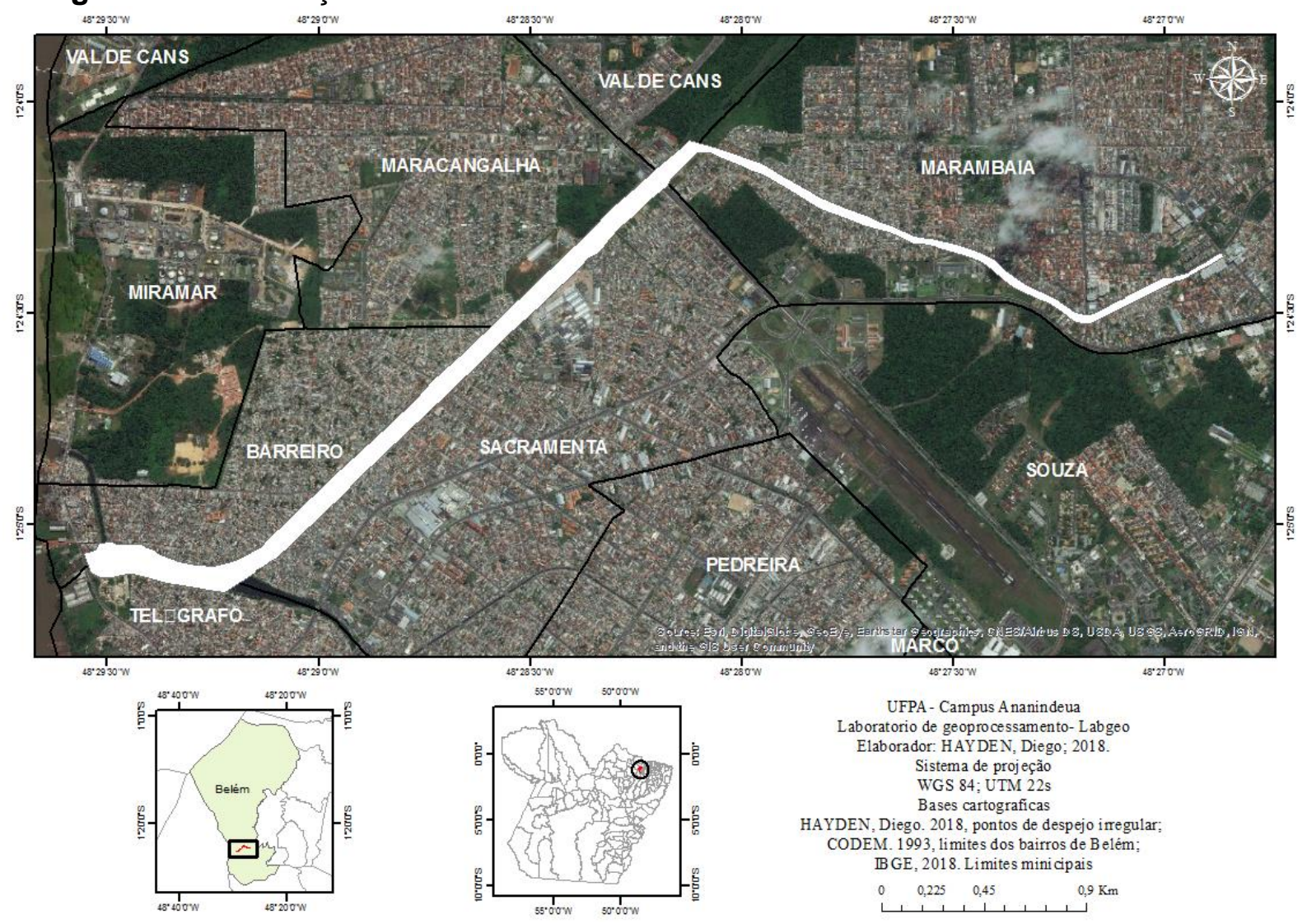

Fonte: organizado pelo autor de IBGE (2010) e Belém (2014).

As características atuais dessa área refletem a segregação socioespacial do modo de produção capitalista no espaço urbano que fragmenta e, ao mesmo tempo, articula os espaços, reproduzindo uma dinâmica de "favelização" das baixadas (SANTOS; PIMENTEL, 2013) que funcionam como um processo de periferização social, no sentido de expressarem nitidamente as marcas da exclusão e da segregação, refletidas por intermédio da habitação de uma classe menos abastada; de uma ocupação de estruturas consideradas desordenadas; de uma infraestrutura viária deteriorada; concentração de lixo; poluição no leito dos canais, bem como da omissão do poder público a respeito das responsabilidades em garantir serviços considerados básicos à reprodução social de forma digna. Assim, este trabalho pretende fomentar o debate sobre a responsabilidade do Estado no que diz respeito à degradação 
ambiental, sobretudo da espacialização dos lixões urbanos (depósitos irregulares de lixo) na beira de canais, em zonas periféricas do município de Belém. Para isso, a metodologia foi dividida em três momentos distintos, a saber:

- Revisão bibliográfica sobre limpeza urbana e gestão de resíduos;

- Trabalho de campo para aquisição de pontos de GPS, mensuração espacial dos depósitos irregulares de lixo e aplicação de entrevistas estruturadas a moradores da área, sobretudo os mais antigos; e

- Beneficiamento de informações em laboratório, na seguinte ordem: classificação de tipos de resíduos sólidos; o cálculo matemático (regra de três simples) de área, em metros quadrados $\left(\mathrm{m}^{2}\right)$, dos depósitos irregulares de resíduos sólidos; produção cartográfica, mediante software de geoprocessamento, de mapas de localização da área de estudo e dos pontos de descarte de resíduos sólidos irregulares e criação de tabelas.

\section{A PRODUÇÃO DO LIXO NA HISTÓRIA}

O lixo, tal qual sua gestão, é um tema global de grande relevância na atualidade devido a vários fatores, como: o modo de vida nas cidades e no campo, consumismo, reciclagem e educação ambiental, entre outros. No Brasil, a questão da disposição do lixo e tratamento de resíduos sólidos ainda está pouco amadurecida e não se encontra equacionada a outras medidas e políticas (SILVA, 2017).

É preciso conhecer o lixo gerado por uma cidade ou por uma comunidade bem como as diversidades deste (formas, tamanhos e composição) para promover melhores soluções de gestão e tratamento dos resíduos, sobretudo por se destacar como ator privilegiado em todo o processo gestacional.

É importante aferir como o estado pensa, interage e opera no gerenciamento do lixo. Tal fato justifica-se pelo papel exercido pela União/estado/município num amplo rol de procedimentos e responsabilidades técnicas e operacionais, não só na elaboração dos planos de gestão integrada, mas, também, nas estratégias relacionadas ao monitoramento e intervenção na remediação, destinação e disposição final do lixo; bem como na contextualização a respeito dos debates sobre os riscos e as vulnerabilidades socioambientais das populações citadinas.

Segundo Waldman (2012b), o crescimento exponencial da distribuição espacial dos depósitos irregulares de lixo/lixões tem como palco privilegiado as metrópoles. Para ele, é indiscutível a participação do Brasil nesse debate, visto que a quantidade de resíduos lançados a céu aberto só tem aumentado e "[...] uma clara demonstração dessa assertiva é que apesar de a população brasileira ter crescido aproximadamente 15\% entre 1991-2000, o lixo domiciliar expandiu-se em 49\%" (INSTITUTO BRASILEIRO DE ADMINISTRAÇÃO 
MUNICIPAL, 2010, p. 2). Tal fato foi possível, no Brasil - segundo Marques (2014), ao falar sobre problemas socioambientais - devido à insuficiente infraestrutura, pela concentração da pobreza, pela cooperatividade empresarial e pela lógica de distribuição desigual dos danos ambientais. Para Abramovay, Speranza e Petitgand (2013, p. 22):

[...] as cidades do planeta produzem hoje 1,3 bilhão de toneladas anuais de resíduos sólidos. A geração de lixo per capita quase dobrou nos últimos anos, chegando na segunda década do milênio a 1,2 quilo por pessoa por dia, segundo o Banco Mundial. O lixo cresce bem mais que a taxa de urbanização, em termos globais. O ritmo desse aumento deve ser arrefecido, mas, com a expansão da população e da renda, a estimativa é que em 2020 sejam atingidos 2,2 bilhões de toneladas anuais de resíduos sólidos.

De forma geral, para a maioria das lideranças administrativas, a questão do lixo é entendida e encarada como um problema meramente estético. Tal entendimento produz medidas paliativas que se traduzem em afastar, dos olhos e das narinas, os incômodos e apresentar falsas soluções à população produtora desses resíduos (FADINI; FADINI, 2001). Assim, a questão da produção do lixo remete-nos a uma discussão sobre o modelo de desenvolvimento escolhido em vários países do mundo que, de acordo com Martine e Alves (2015), se traduzem na necessidade do aumento do consumo em diversos níveis que nos convencem diariamente de que precisamos comprar e consumir cada vez mais, favorecendo alguns e excluindo muitos, sendo, portanto, predatório e com acentuada exclusão social.

É notório que o crescimento econômico se atentou mais no sentido de desenvolvimento de produtos oferecidos no mercado e bem menos na destinação final dos resíduos deles advindos. Desse modo, os problemas, advindos do exponencial aumento da produção de lixo e dos depósitos irregulares destes, estão ligados diretamente à forma de como a sociedade produz e consome seus produtos. Assim, devido ao desenvolvimento dos produtos industriais e das embalagens que com eles se adquire, a formação do lixo urbano e mesmo rural mudou em complexidade e dificuldade de tratamento, sem que isso implicasse em uma mudança real frente às condições da disposição final do lixo produzido. Dessa forma, se estas não forem devidamente enfrentadas serão e/ou continuarão sendo uma ameaça à saúde pública e ao meio ambiente.

Os debates sobre a questão da produção de lixo têm sido amplamente presentes em escala mundial em vários fóruns internacionais e os especialistas apontam uma solução que seria o consumo de forma sustentável, o que implica em poupar os recursos naturais, conter o desperdício, "diminuir" a produção, aumentar a reutilização e a reciclagem da maior quantidade de resíduos possível (BRASIL, 2012). 
A composição dos lixões é variada e depende dos lugares em que são produzidos. O Banco Mundial propõe uma classificação, de acordo com Abramovay, Speranza e Petitgand, (2013, p. 23):

O Banco Mundial [...] propõe uma classificação em seis categorias, que se decompõem, cada uma, em vários tipos: lixo orgânico, papel, plástico, vidros, metais e outros. A essa lista devem ser acrescidos os que decorrem da construção civil (que, segundo o Banco Mundial, algumas vezes correspondem a $40 \%$ da massa total dos resíduos de uma cidade) e aqueles que, embora resultem do consumo dos indivíduos, não pertencem habitualmente aos sistemas de coleta domiciliar: óleos lubrificantes e suas embalagens, pneus, embalagens de agrotóxicos e resíduos dos serviços de saúde.

Da mesma forma, os resíduos podem ser tratados de três formas distintas (BRASIL, 2012): I - Aterramento que pode ser expresso na forma de aterro sanitário e aterro controlado, que, no entanto, é mais uma forma de disposição do lixo do que de tratamento deste; II incineração caracterizada por proporcionar uma transformação térmica dos resíduos a temperaturas que variam de $800^{\circ} \mathrm{C}$ a $1000^{\circ} \mathrm{C}$, que ficam reduzidos a cerca de $10 \%$ de seu volume inicial e III - reciclagem que é o conjunto de atividades e processos que objetivam promover o reaproveitamento de componentes, como: o plástico, o papel, os metais ferrosos, o alumínio e o vidro, entre outros.

É preciso frisar que todas as alternativas de tratamento de lixo apresentam vantagens e desvantagens o que, por si só, já é uma boa justificativa para considerar a não geração de lixo como a melhor opção. No entanto, o modelo de gestão integrada torna-se um importante instrumental na gestão dos resíduos sólidos (FADINI; FADINI, 2001), visto que, por meio dessa, é possível adotar um conjunto articulado de ações normativas, operacionais, financeiras e de planejamento, com base em critérios sanitários, ambientais e econômicos para coletar, tratar e dispor o resíduo sólido.

Isso porque a execução de ações planejadas, de forma racional e integrada, leva ao gerenciamento adequado do lixo, assegurando saúde, bem-estar e economia de recursos públicos, além de ir ao encontro de um desejo maior que é a melhoria da qualidade de vida das gerações atuais e futuras.

A produção de lixo, no Brasil, vem aumentando significativamente, principalmente, nas regiões metropolitanas e grandes cidades. A questão da disposição regular e irregular do lixo e do tratamento de resíduos ainda está pouco amadurecida. Os relatórios anuais da Associação Brasileira de Empresas de Limpeza e Resíduos Especiais (ABRELPE) mostram que a quantidade de lixo, no Brasil, cresce mais que a população, sendo que a distribuição, majoritariamente, é realizada em lixões. 
Para se ter uma base dessa situação, foi constatado que apenas 0,01\% é incinerado, $1 \%$ tratado em usinas de compostagem, $9 \%$ são destinados a aterros sanitários, $12 \%$ são dispostos em aterros controlados e $78 \%$ são lançados em lixões regulares e irregulares (WALDMAN, 2012a). Fato que contribui para o descarte irregular de lixo para "longe" dos olhos da população em lugares, sobretudo, pouco assistido pelo poder público, como: terrenos baldios e canais urbanos, entre outros.

No Brasil, o dever do gerenciamento dos resíduos sólidos é de competência do poder público local, mas a "[...] prática comum da maioria das administrações municipais é a de colocar resíduos em lixões a céu aberto ou em aterros sem nenhum controle, resultando em perdas ambientais, sociais e econômicas" (SILVA, 2017, p. 198). É obrigação dos municípios elaborarem planos de gestão dos resíduos, incentivar a coleta seletiva de lixo, e adotar a responsabilidade compartilhada e da gestão integrada do lixo, fato que só pode ser possível dependendo da interface política do lixo. Para Waldman (2012a, p. 2):

[...] o lixo possui uma interface política, que se revela toda vez que se coloca o debate sobre sua destinação, gestão, discriminação de responsabilidades, encaminhamento das normatizações e sumamente, a aplicação das leis. Outro problema, este premente pela sua determinação espacial, é a escassez de áreas para disposição de lixo domiciliar.

A face política pode ser expressa na determinação espacial e na escassez de áreas para disposição de lixo domiciliar, pois muitas cidades e/ou regiões metropolitanas não têm estoque de terras disponíveis para a construção de novos aterramentos. Cada aterro que cessa suas atividades significa um desafio geralmente insolúvel (WALDMAN, 2012a). E, além disso, o funcionamento dos lixões/depósitos irregulares de lixo afeta a saúde e viola os direitos humanos das centenas de milhões de pessoas que vivem nesses locais ou no seu entorno (INTERNATIONAL SOLID WASTE ASSOCIATION, 2017).

\section{GESTÃO DOS RESÍDUOS SÓLIDOS EM BELÉM}

De forma geral, a cidade de Belém vem sofrendo há anos com problemas relacionados à destinação final do lixo, bem como da crescente espacialização de depósitos irregulares desses resíduos, fato este que se expressa nitidamente nos bairros periféricos, sobretudo nas áreas de baixada, esta geralmente recortada por igarapés canalizados, que as tornam em áreas com grandes problemas ambientais, visto que o aumento do volume de lixo se distribui em locais irregulares, contaminando a água e o solo, empesteando o ar com odores desagradáveis e transmitindo uma gama de doenças por meio de vetores que se localizam nesses espaços. 
É preciso deixar claro que a questão da gestão do lixo é uma competência comum entre União, estados e municípios, mas é a este último que cabe estabelecer as condições técnicas, administrativas, financeiras e institucionais para a gestão dos resíduos sólidos.

Em Belém cabe à Secretaria de Saneamento (SESAN) a promoção, a coordenação, a execução e a fiscalização dos mecanismos que visam a proteção do meio ambiente e o combater a poluição em qualquer de suas formas e, para isso, promover condições dignas de saneamento, por meio, nesse caso, do recolhimento regular de lixo de acordo com a necessidade de cada área na cidade. Nesse contexto, surge o Plano de Gerenciamento Integrado de Resíduos Sólidos como um conjunto de ações exercidas em todo o processo de gestão dos resíduos sólidos, contemplando um modelo de coleta, tratamento e destinação final do lixo, ou seja, do serviço de coleta dos resíduos, respeitando as características de heterogeneidade do lixo urbano, como exposto no Art. 9요 1ํ․ 2o (BELÉM, 2011):

Art. 9 O Plano de Gerenciamento de Resíduos Sólidos do Município de Belém contempla um modelo de coleta, tratamento e destinação final dos resíduos sólidos.

$\S 1 \%$. O serviço de coleta será diferenciado por tipo de resíduo, tendo em vista respeitar as características de heterogeneidade do lixo urbano, facilitar o tratamento, favorecer o reaproveitamento, racionalizar a utilização de pessoal e equipamentos, otimizando os custos operacionais.

$\S 2$ 응 O serviço de coleta foi dividido em quatro categorias: coleta domiciliar/comercial, coleta de entulho, coleta de serviços congêneres e dos Resíduos de Serviços de Saúde (RSS).

Tal processo de gerenciamento objetiva minimizar os impactos ambientais decorrentes de resíduos oriundos de atividades humana, assegurando, dessa maneira, a preservação do meio ambiente, alocando-os em aterro sanitário devidamente licenciado pelo órgão ambiental competente.

\section{ALGUMAS CONSIDERAÇÕES SOBRE O DEVER DO ESTADO}

Todas as leis que regem a sociedade e, nesse caso, especificamente, a gestão dos resíduos sólidos fazem parte de um conjunto de ações debatidas e propalados pelo Estado em diversos níveis que se fundamentam em garantir uma "equidade" social a partir da repartição de ganhos e perdas decorrentes de atos ou efeitos socialmente danosos, evitando que alguns suportem prejuízos ocorridos por ocasião ou por causa de atividades desempenhadas no interesse de todos (CAVALIERI FILHO, 2011). Mas, o que fazer quando o Estado se omite e não realiza o que é estipulado legalmente ou realiza parcialmente?

Existe no direito brasileiro, o conceito de responsabilidade civil do Estado, segundo Pinto (2015) e Lopes (2013), que implica em pesquisar os princípios e as razões que levam o ordenamento jurídico e a jurisprudência a reconhecerem o dever de o Estado ressarcir os 
prejuízos causados, em algumas hipóteses, seja por atos lícitos (quando a causa geradora de obrigação da gestão é estipulada por meio de contrato e/ou declaração unilateral de vontade) ou ilícitos (quando há pressuposto de culpa Lato sensu, ou seja, a intenção do agente de prejudicar outrem, a violação de um direito, o prejuízo causado por negligência, imprudência ou imperícia) (PINTO, 2015). Essa responsabilidade civil do Estado é caracterizada de duas formas:

- Responsabilidade objetiva quando o Estado responde pelos danos que os seus agentes, nessa qualidade, causarem a terceiros. As ações de seus agentes, nessa qualidade, estão e evidenciam a teoria do risco administrativo (que é, grosso modo, uma expressão democrática de repartir os ônus e encargos sociais por todos aqueles que são beneficiados pela atividade da administração pública) como fundamento da responsabilidade do Estado; isto é, aos casos em que houver relação de causa e efeito entre a atuação do agente público e o dano (CAVALIERI FILHO, 2011). Para que essa responsabilidade seja aplicada "[...] não há a necessidade da prova da culpa, bastando à existência do dano, da conduta e do nexo causal entre o prejuízo sofrido e a ação do agente. A responsabilidade está calcada no risco assumido pelo lesante, em razão de sua atividade" (LOPES, 2013, p. 2).

- Responsabilidade subjetiva quando o Estado é omisso, fornece um trabalho com funcionamento tardio ou mesmo com funcionamento ineficiente de forma genérica. "[...] se o Estado não agiu, não pode, logicamente, ser ele o autor do dano. [...] só cabe responsabilizálo caso esteja obrigado a impedir o dano. Isto é: só pode responsabilizá-lo se descumpriu o dever legal que lhe impunha obstar o evento lesivo" (CAVALIERI FILHO, 2011, p. 16), ou seja, para esta caracterização, segundo Lopes (2013, p. 2) "[...] devem coexistir os seguintes elementos: a conduta, o dano, a culpa e o nexo de causalidade entre a conduta e o dano".

De forma geral, há uma confluência entre as leis que regem as políticas e planos nacionais de resíduos sólidos, a Lei Orgânica do Municipal e o Plano de Gerenciamento Integrado de Resíduos sólidos de Belém. Estes confluem nos objetivos quanto à destinação final ambientalmente adequada por intermédio da reutilização (a reciclagem, a compostagem e a recuperação); do gerenciamento de resíduos sólidos como o conjunto de ações exercidas, direta ou indiretamente, nas diversas etapas do manuseio do lixo (de coleta, transporte, transbordo, tratamento e destinação final); da gestão integrada de resíduos sólidos (considerando a busca de soluções nas dimensões política, econômica, ambiental, cultural e social) e quanto à responsabilidade compartilhada pelo ciclo de vida dos produtos.

Essas diretrizes objetivam promover a integração da organização, do planejamento e da execução das funções públicas que regem a gestão dos resíduos sólidos nas regiões metropolitanas e aglomerações urbanas, além de controlar e fiscalizar as atividades dos geradores de lixo, sujeitas a licenciamento ambiental. 
Na prática, tais leis, apesar de inovadoras e abrangentes, não conseguem sanar os problemas decorrente da má gestão dos resíduos sólidos em lugares regulares e irregulares de depósito de lixo.

\section{ESTUDO DE CASO}

A área em estudo é caracterizada por estar inserida em uma das maiores bacias hidrográficas da cidade de Belém, a Bacia do Una, na confluência de cinco bairros periféricos e que sofreu transformações decorrentes da ação do Estado, no projeto de macrodrenagem. A paisagem atual deste espaço demonstra uma segregação socioespacial que articula uma dinâmica de favelização refletida nas diversas formas existentes (ruas, casas e avenidas, entre outros) e na dinâmica social (distribuição irregular de lixo e violência, por exemplo). Nesse espaço, é evidente a pouca ação do poder público no sentido de sanar tais problemas, sobretudo nesse caso dos depósitos irregulares de lixo que proliferam, crescendo sobremaneira e fazendo parte do cotidiano dos moradores da área.

O trabalho de campo revelou 36 pontos irregulares de depósito de lixo com diversos tamanhos, conforme a Figura 2. Isso equivale a aproximadamente 13 mil metros quadrados de área de lixo, em um espaço de aproximadamente 320,000 metros quadrados, conforme a Tabela 1.

É preciso frisar também que apesar de estarmos em consonância com a classificação do Plano de Gerenciamento Integrado de Resíduos Sólidos do Município de Belém - que classifica os resíduos sólidos, como: resíduos domiciliares, resíduos de limpeza urbana, resíduos sólidos urbanos, resíduos de estabelecimentos comerciais e prestadores de serviços, resíduos dos serviços públicos de saneamento básico, resíduos industriais, resíduos de serviços de saúde, resíduos da construção civil, resíduos agrossilvopastoris, resíduos de serviços de transportes e resíduos de mineração (BELÉM, 2011) - optamos em classificar os resíduos encontrados para facilitar a análise, como: lixo doméstico (resto orgânico de alimentos, sacola, embalagem plásticas e metálicas de descartáveis); lixo doméstico/móveis (colchões, sofás, cascos de geladeira e eletrodomésticos, entre outros); papéis (livros, revistas, cadernos e papelões); madeira e podas de árvores; caroços de açaí; entulhos (resto de construção civil) e pneus/vidros, conforme a Tabela 2. 
Figura 2 - Distribuição espacial dos depósitos irregulares de lixo

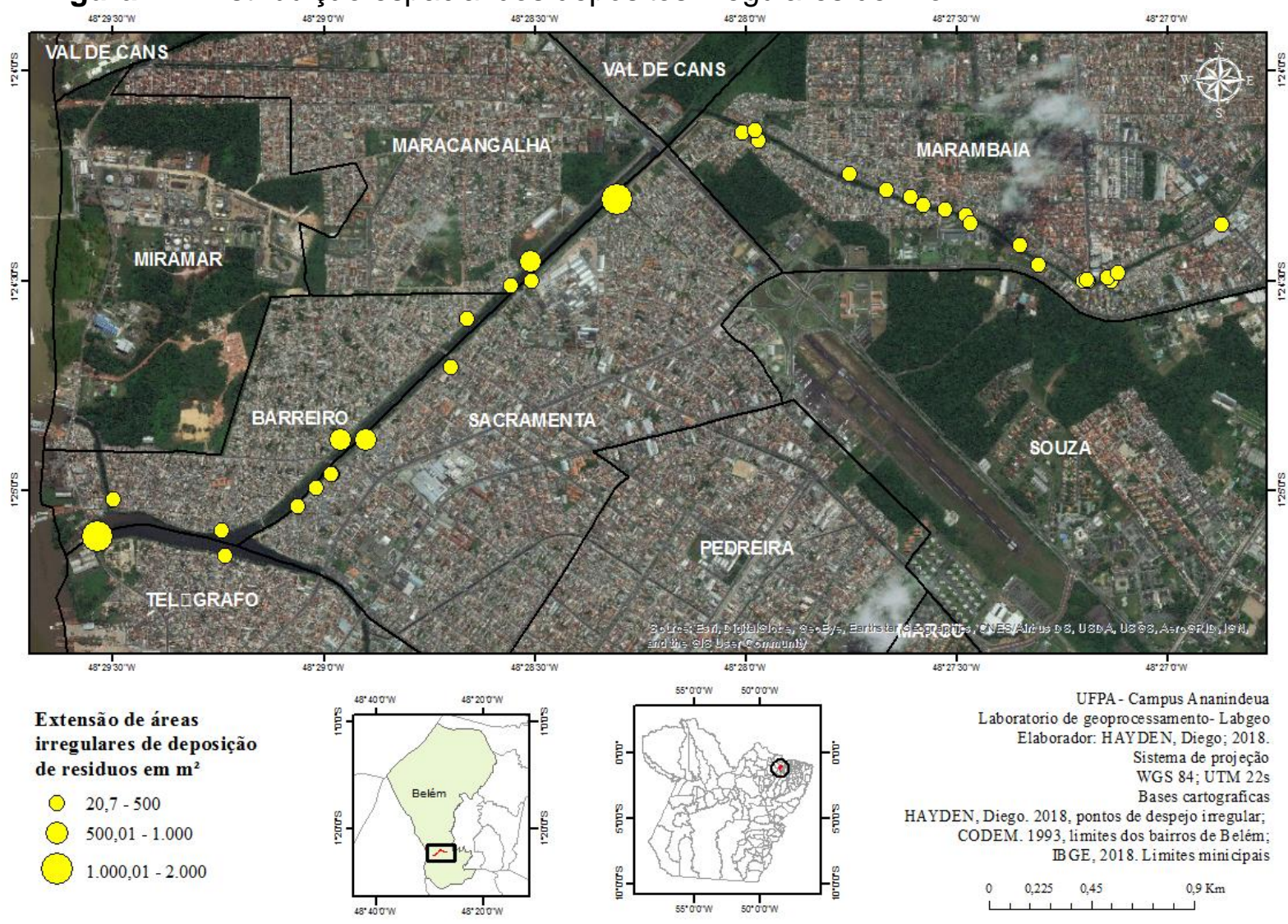

Fonte: Organizado pelo autor de: IBGE (2010) e Belém (2014).

Tabela 1 - Distribuição espacial do lixo

Distribuição espacial em M de áreas de despejos irregulares de resíduos sólidos

\begin{tabular}{|c|c|c|c|c|}
\hline & Comprimento da área $\mathrm{m}^{2}$ & $\begin{array}{l}\text { Comprimento } \\
\text { em } \mathrm{m}\end{array}$ & \begin{tabular}{|l} 
Largura \\
em $\mathrm{m}$
\end{tabular} & $\begin{array}{l}\text { Área de lixo } \\
\mathrm{em} \mathrm{m}^{2}\end{array}$ \\
\hline Total & 320.000 & $1.193,70$ & 320,2 & 12.929 \\
\hline
\end{tabular}

Fonte: o próprio autor, 2018.

Tabela 2 - Tipos de resíduos e quantidades de locais encontrados

\begin{tabular}{|l|c|c|c|l|l|l|l|c}
\hline \multicolumn{7}{|c|}{ Principais pontos resíduos encontrados e suas porcentagens (\%) } \\
\hline $\begin{array}{l}\text { Total de } \\
\text { pontos }\end{array}$ & Doméstico & $\begin{array}{l}\text { Doméstico } \\
\text { (móveis) }\end{array}$ & $\begin{array}{l}\text { Livros/ } \\
\text { revistas/pa } \\
\text { pelões }\end{array}$ & $\begin{array}{l}\text { Madeiras/p } \\
\text { odas de } \\
\text { arvores }\end{array}$ & $\begin{array}{l}\text { Caroços } \\
\text { de açaí }\end{array}$ & $\begin{array}{l}\text { Construção } \\
\text { (entulho) }\end{array}$ & $\begin{array}{l}\text { Pneus } \\
\text { /vidro }\end{array}$ \\
\hline Pontos & 36 & 22 & 6 & 2 & 25 & 13 & 17 & 2 \\
\hline & 100 & 61,11 & 16,66 & 5,5 & 69,44 & 36,11 & 47,22 & 5,5 \\
\hline
\end{tabular}

Fonte: o próprio autor, 2018.

Todos esses depósitos irregulares se distribuem espacialmente de forma "homogênea" ao longo de todo o trecho estudado, porém com conteúdos heterogêneos, conforme a Figura 3. Os principais tipos de resíduos encontrados foram: 
- Os classificados como madeira/podas de árvores que estão localizados em 69,44\%, dos pontos identificados, tal fato é decorrente da "melhoria" da qualidade das residências (ou seja, da construção de casas de alvenaria em lugar das de madeira), da poda das árvores residenciais e nas margens dos canais, realizada pelos moradores e as trazidas por carroceiros ambulantes de outros lugares e da não manutenção, por parte da Secretaria Municipal de Meio Ambiente (SEMAS), das áreas vegetadas nesses espaços.

- O segundo tipo de resíduos mais vistos nos depósitos irregulares foram os domésticos, localizados em $61,11 \%$ dos pontos. Isso decorre em boa medida da insuficiência da coleta seletiva e/ou da falta de regularidade do recolhimento de tais resíduos.

- O terceiro foram os restos de construções civis (entulhos), correspondendo a 47,22\% dos resíduos encontrados. Esse tipo de resíduo é originadas das transformações das formas espaciais/infraestruturas públicas e privadas, tanto nas residenciais quanto nas vias de circulação das áreas próximas; tal resíduo geralmente é direcionado a essas áreas por carroceiros.

- Outro tipo de resíduo muito encontrado foi o caroço de açaí, localizado em $36,11 \%$ dos pontos de descarte irregular, oriundos dos comércios da polpa do açaí que se espalham por toda área estudada.

- Os resíduos domésticos (móveis) representados por sofás velhos, estantes deterioradas, cascos de geladeira, entre outros que, juntos, representam $16,66 \%$ dos pontos de descarte irregular de resíduos decorrentes, principalmente da aquisição de novos objetos trazidos, sobretudo, por carroceiros de moradores da área e do entorno.

- E por fim os livros/revistas/papelões e pneus/vidro que não atingem $6 \%$ dos pontos de descarte irregular.

Figura 3 - Depósitos irregulares de lixo as margens dos canais São Joaquim e Água Cristal

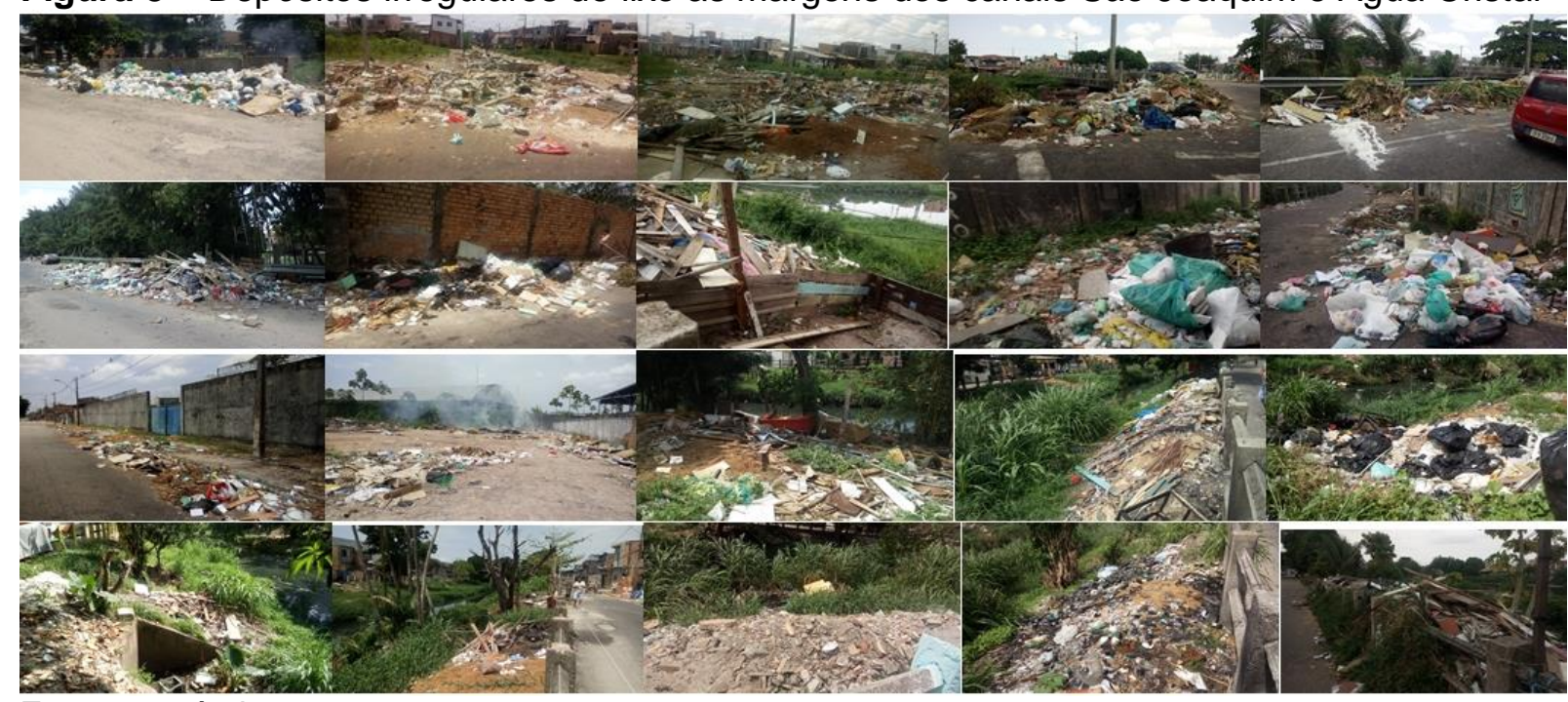

Fonte: o próprio autor, 2018. 
É importante frisar que em toda a extensão da área estudada há uma prática de redução do volume de lixo que é expresso por meio da queima, principalmente de madeira/poda de árvores, e também de resíduos domésticos (móveis), livros/ revistas/papelões e pneus/vidro e da utilização de restos de construção civil (entulho) para a construção de espaços de sociabilidades, como: jardins, praças, espaços para esporte e lazer, fato que torna a percepção falsa de uma menor quantidade de lixo nas vertentes dos canais.

Essa grande quantidade de resíduos, é importante destacar, é oriunda, em parte, dos moradores do entorno do canal/beira, mas também de áreas/ruas longínquas, cujos detritos são recolhidos por carroceiros nos mais diversos locais (mercadinhos, açougues e feiras, entre outros).

O serviço de coleta seletiva é/ou deve ser realizado com base no Plano de Gerenciamento de Resíduos Sólidos Municipal, tendo uma lógica que contempla a coleta, tratamento e destinação final dos resíduos sólidos, que é realizada de forma diferenciada, de acordo com o tipo de resíduo e de sua heterogeneidade, pelo menos em tese (BELÉM, 2011), a fim de facilitar o tratamento, favorecer o reaproveitamento, racionalizar a utilização de pessoal e equipamentos e otimizar os custos operacionais, dividindo os resíduos em quatro categorias: coleta domiciliar/comercial, coleta de entulho, coleta de serviços congêneres e dos Resíduos de Serviços de Saúde (RSS).

Apesar de ser o município quem estabelece normas para a coleta seletiva de lixo, não é ele quem regula a frequência da coleta, esta é estabelecida pelo Operador de Serviços de Limpeza Urbana (empresa privada de coleta seletiva), que geralmente a faz com a temporalidade de três vezes por semana.

Cabe ressaltar que, neste trabalho, analisaremos somente as duas primeiras classificações do Plano de Gerenciamento de Resíduos Sólidos de Belém, tratando os resíduos domésticos como domésticos/comercial e o entulho como todos os demais tipos de resíduos expostos no trabalho.

Segundo os dados coletados em campo a coleta desses tipos de resíduos acontece de forma diferente: $87,5 \%$ dos entrevistados apontaram que há regularidade na coleta do lixo doméstico (resíduos doméstico/comercial). Desses casos, $75 \%$ apontam que as coletas ocorrem menos de três vezes na semana e $25 \%$ afirmaram que a regularidade corresponde a três ou mais vezes na semana. $12,5 \%$ dos entrevistados declararam não haver nenhuma regularidade.

Se considerarmos a coleta seletiva dos outros tipos de resíduos (entulhos), 75\% dos entrevistados garantiram que há regularidade, mas estas são dadas de formas desordenadas, ou seja, sem um calendário especifico, em dias aleatórios. Desses, 50\% afirmaram que a frequência das coletas varia de uma vez ao mês (25\%) a cinco vezes ao ano (25\%) e 50\% 
não souberam responder, mas afirmaram haver regularidade. $25 \%$ certificaram não haver regularidade alguma de coleta desses resíduos, como mostra a Tabela 3.

Tabela 3 - Coleta de resíduos sólidos

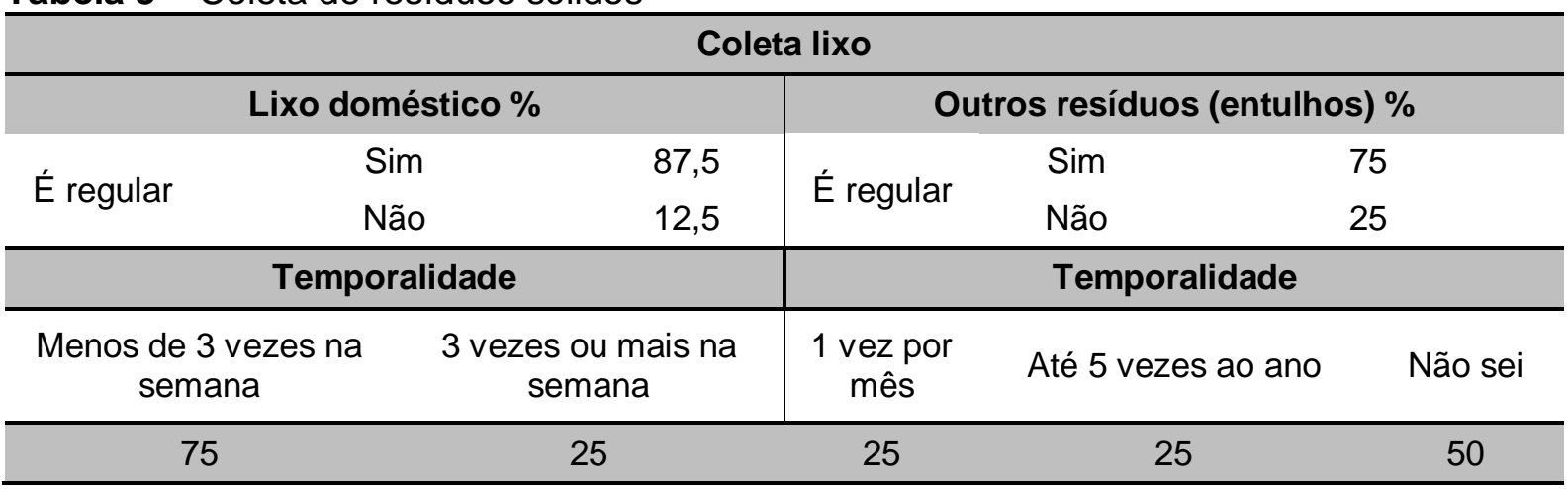

Fonte: o próprio autor, 2018.

Um fator interessante para análise é quando se pergunta sobre a gestão espacial do lixo pelo município, considerando a falta de estratégia para a limpeza, uma vez que é consenso por parte dos entrevistados a falta de qualquer tipo de política, para além do recolhimento dos resíduos, desde as de educação ambiental em lócus até as de fiscalização e repressão. Tal fato contribui, sobremaneira, para a falta de responsabilidade da população da beira, mas, sobretudo, da população de entorno e dos carroceiros que são os grandes depositários de resíduos.

Os moradores localizados nas margens/beira dos canais, segundo as entrevistas, também revelaram sentirem-se de "mãos atadas" quando perguntados sobre suas ações para amenização ou término dos depósitos irregulares de lixo às margens dos canais, devido a possibilidade de agressões físicas e/ou orais por parte, sobretudo, dos carroceiros.

Tais fatos contribuem para a manutenção dos espaços de depósito irregulares de lixo, visto que $75 \%$ dos entrevistados afirmaram a existência de tais lugares há mais de cinco anos, sendo, destes, $62,5 \%$ superior a 11 anos de manutenção; e $25 \%$ declararam que a existência de tais lugares compreende um tempo que transita de um a cinco anos. Nenhum dos entrevistados afirmou que tais depósitos de lixo existiam até um ano, conforme a Tabela 4.

Tabela 4 - Tempo de existência dos depósitos irregulares de lixo no Canal São Joaquim e Água Cristal

\section{Tempo de existência dos depósitos irregulares de lixo}

\begin{tabular}{ccccc}
\hline Tempo & Até 1 ano & De 1 a 5 anos & De 6 a 10 & De 11 em diante \\
$\%$ & 0 & 25 & 12,5 & 62,5 \\
\hline
\end{tabular}

Fonte: o próprio autor, 2018. 
A naturalização do lixo por partes dos cidadãos, em conjunto com a falta de postura política dos gestores para a manutenção e valorização das áreas periféricas/baixadas, contribui para a manutenção e ampliação dos depósitos irregulares de lixo, pois não há ou pouco acontece de mobilização popular (individual ou comunitária) em busca da extinção e/ou redução das áreas irregulares.

É importante frisar que, nesse contexto, não foi ou pouco foi exposto pelos entrevistados, quando perguntados sobre as dificuldades trazidas pelo lixo, menção a problemas de saúde coletiva, de odores desagradáveis ou proliferação de pragas urbanas (moscas, baratas, ratos, entre outros) decorrente do depósito de lixo. Desse modo, ficou evidente que o problema do lixo nessa área é meramente estético.

\section{CONCLUSÃO}

Apesar da confluência legal das leis - que regulam a gestão de resíduos sólidos na esfera federal, estadual e municipal, visando uma destinação final, ambientalmente adequada, por intermédio da organização, do planejamento e da execução de tais normas na prática -, em Belém, sobretudo, nas áreas de periferias, estas não conseguem sanar os problemas decorrentes da má gestão dos resíduos sólidos em lugares regulares e irregulares de depósito de lixo.

$\mathrm{Na}$ área estudada, por exemplo, os resíduos sólidos se espalham homogeneamente por todos os lados a partir de diversas classificações (são lixos domésticos, podas de árvores, entulhos etc.) e com frequências diferenciadas, sobretudo de entulho, madeira/podas de árvores e lixo doméstico. Tais resíduos têm coleta seletiva que é realizada de forma distinta para lixos domésticos que são recolhidos, majoritariamente, de uma a duas vezes na semana e entulhos que são recolhidos, de forma geral, em tempos não exatos, mas superior a cinco vezes ao ano.

Há uma naturalização em torno dos depósitos irregulares de lixo por parte dos moradores da beira do canal, bem como dos lugares do entorno. Os cidadãos, em conjunto da falta de postura política dos gestores para a manutenção e valorização das áreas periféricas/baixadas, contribuem para a manutenção e ampliação dos depósitos irregulares de lixo, visto que toda a política que envolve a gestão dos resíduos sólidos não é aplicada ou é aplicada parcialmente, fato observável na temporalidade da coleta de resíduos domésticos e entulhos; na temporalidade de existência desses lugares de despejo irregular que são superiores, em grande parte, a seis anos de existência; na falta de educação ambiental em lócus; na repressão a tal prática pelo "poder" responsável (polícia ambiental); e na falta de plano abrangente e aplicável de reciclagem, entre outros. 
Enfim, o término e/ou a minimização da distribuição espacial de depósitos irregulares de lixo requerem uma cooperação para além da letra, por meio das formas efetivas de ação entre sociedade civil e gestão pública, nesse caso, municipal. É preciso deixar claro que a gestão da limpeza não é meramente estética e é um dever de todos, além de uma problemática sistêmica por influenciar vários ramos da vida cotidiana, desde a saúde coletiva, a gestão e a educação ambiental, a economia do lixo e a consciência política.

\section{REFERÊNCIAS}

ABRAMOVAY, R.; SPERANZA, J. S; PETITGAND, C. Lixo zero: gestão de resíduos sólidos para uma sociedade mais próspera. São Paulo: Planeta Sustentável: Instituto Ethos, 2013.

BELÉM. Lei Ordinária N. 8899, de 26 de dezembro de 2011. Belém: Câmara Municipal, 2011. Disponível em: https://leismunicipais.com.br/a/pa/b/belem/lei-

ordinaria/2011/890/8899/lei-ordinaria-n-8899-2011-institui-o-plano-de-gerenciamentointegrado-de-residuos-solidos-do-municipio-de-belem-pgrs-e-da-outras-providencias. Acesso em: 6 dez. 2018.

BELÉM. Prefeitura Municipal. Companhia de Desenvolvimento e Administração da Área Metropolitana. Mapa dos Bairros de Belém. Belém: CODEM, 2014. Disponível em: http://www.belem.pa.gov.br/codem_mapas/Mapas_PDF/Bairros/Mapa\%20Geral\%20\%20Bairros\%20de\%20Belem.pdf. Ácesso em: 20 dez. 2019.

BRASIL. Ministério do Meio Ambiente. Plano Nacional de Resíduos Sólidos. Brasília: MMA, 2012. Disponível em:

http://sinir.gov.br/images/sinir/Arquivos_diversos_do_portal/PNRS_Revisao_Decreto_28081 2.pdf. Acesso em: 16 dez. 2018.

CAVALIERI FILHO, S. A responsabilidade civil objetiva e subjetiva do Estado. Revista da EMERJ, Rio de Janeiro, v. 14, n. 55, p. 10-20, jul. /set. 2011.

FADINI, P. S.; FADINI, A. A. B. Lixos: desafios e compromissos. Cadernos Temáticos de Química Nova na Escola, São Paulo, SP, v. 1, p. 9-18, maio 2001. Edição especial. Disponível em: http://qnesc.sbq.org.br/online/cadernos/01/lixo.pdf. Acesso em: 16 jan. 2019.

IBGE. Cartas e Mapas. Mapas municipais. 2010. Disponível em:

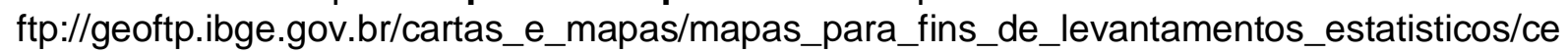
nso_demografico_2010/mapas_municipais_estatisticos/. Acesso em: 20 dez. 2019.

INSTITUTO BRASILEIRO DE ADMINISTRAÇÃO MUNICIPAL - IBAM. Manual gerenciamento integrado de resíduos sólidos. Rio de Janeiro, 2001.

INTERNATIONAL SOLID WASTE ASSOCIATION - ISWA. Roteiro para encerramento de lixões: os lugares mais poluídos do mundo. São Paulo, SP: Abrelpe, 2017. Disponível em: www.iswa.org. Acesso em: 14 maio 2017.

LOPES, A. L. Responsabilidade civil do estado: roteiro de estudos. Belo Horizonte: Escola Superior Dom Elder Câmara, 2013. Disponível em: https://domtotal.com/direito/uploads/pdf/12381f8050a9ddd8995da932c6e03388.pdf. Acesso em: 14 nov. 2018.

MARQUES, C. As permanências dos desafios ambientais nos espaços urbanos. R. bras. Est. Pop. Rio de Janeiro, v. 31, n.12, p. 483-489, jul./dez. 2014.

MARTINE, G.; ALVES, J. E. D. Economia, sociedade e meio ambiente no século 21: tripé ou trilema da sustentabilidade? Revista Brasileira de Estudos de População, Rio de Janeiro, v. 32, n. 3, p. 433-460, 2015. 
PINTO, H. E. Fundamentos da responsabilidade civil do estado. Revista de Direito Administrativo e Gestão Pública, Belo Horizonte, MG, v. 1, n. 2, p. 87-102, jul. /dez. 2015. SANTOS, M. Pensando o espaço do homem. São Paulo: EDUSP, 2012.

SANTOS, V. C. Requalificação urbana da paisagem de várzea da Vila da Barca Belém/Pará e suas consequências socioambientais. 2012. Dissertação (Mestrado em Geografia) - Universidade Federal do Pará, Belém, 2012.

SANTOS, V. C.; PIMENTEL, M. A. da S. A vila da barca no contexto de ocupação das várzeas de Belém. In: OLIVEIRA, J. M. G. C. (org.). Espaço, natureza e sociedade: olhares e perspectivas. Belém: GAPTA/UFPA, 2013. p. 171-190.

SILVA, E. T. da. Tratamento de lixo domiciliar e sua aplicação na recuperação de áreas degradadas. Revista Acadêmica, Curitiba, v. 5, n. 2, p. 197-209, abr./jun. 2017.

WALDMAN, M. Gestão do lixo domiciliar: considerados sobre a atuação do estado. In: CONFERÊNCIA ECOLOGIA HUMANA E MOVIMENTOS SOCIAIS; SEMANA TEMÁTICA DE BIOLOGIA USP, 15., 2012, São Paulo. Texto de subsídio [...]. São Paulo: Instituto de Biociências da Universidade de São Paulo, 2012a. p. 1-10.

WALDMAN, M. Lixo domiciliar brasileiro: notas sobre processos \& dinamismo sócioespacial. In: SEMANA TEMÁTICA DE BIOLOGIA USP, 15., 2012, São Paulo. Texto de subsídio [...]. São Paulo: Universidade de São Paulo, 2012b. p. 1-10.

\section{AGRADECIMENTOS}

O nosso agradecimento é direcionado às pessoas que possibilitaram o desenvolvimento deste trabalho: as colegas Juliana Lopes de Oliveira e Andressa Hilana Pereira Mercês da Silva, do curso de Pós-Graduação em Geografia e Meio Ambiente; aos colegas pessoais Leonardo Tavares Ferreira e Hualin Amaral da Silva que se disponibilizaram à ida ao árduo trabalho de campo para aquisição de dados; aos professores Dr. Enilson da Silva Sousa, coordenador do curso de Pós-Graduação em Geografia e Meio Ambiente; e ao Dr. Lúcio Correia Miranda, professor do curso de Tecnologia em Geoprocessamento, ambos da UFPA, que nos auxiliaram com algumas orientações do trabalho.

Recebido: agosto de 2019. Aceito: dezembro de 2019. 